\title{
Ring Opening in Epoxy, Propoxy Carbazole with Various Amines Using Ionic Liquid as Green Solvent
}

\author{
G V R Sharma ${ }^{1, *}$, M. Veerraghava Reddy ${ }^{1,2}$, G. Omprakash ${ }^{2}$, K. Tatendra Reddy ${ }^{2}$ \\ ${ }^{1}$ Department of Chemistry, GIT, GITAM University, Visakhapatnam-530 045, India \\ ${ }^{2}$ Pharma Zell R\&D (India) Private Limited, Visakhapatnam- 531 162, India \\ *Corresponding author: sharmagvr@yahoo.co.uk
}

Copyright $@ 2014$ Horizon Research Publishing All rights reserved.

\begin{abstract}
The epoxides undergo ring-opening reaction smoothly with various amines in an ionic liquid namely 1-butyl-3-methylimidazolium tetrafluoroborate $\left(\mathrm{bmim}_{\mathrm{BF}}\right)$ under mild reaction conditions. All the reactions were carried out at ambient temperature to afford the corresponding $\beta$-aminoalcohols in excellent yields. The ionic liquid was recovered and reused in further reactions with very good efficiency.
\end{abstract}

Keywords Epoxides, Amines, Bmim $\mathrm{BF}_{4}, \beta$-Amino Alcohols

\section{Introduction}

$\beta$-Adrenergic blocking agents ( $\beta$-blockers) $)^{1,3-11}$ mostly comprising of $\beta$-amino alcohols are of pharmaceutical significance and have received major attention due to their utility in the management of cardiovascular disorders including hypertension, anginapectoris, cardiac arrhythmias, and other disorders related to the sympathetic nervous system. Aryloxy $\beta$-amino alcohol functionality is the key pharmacophore in $\beta$-blockers. Propranolol is the prototype agent for this class of compounds, which affects $\beta 1$ and $\beta 2$ receptors. The classical approach and the most straight forward synthetic route for the preparation of $\beta$-amino alcohols, involve the heating of epoxide with an excess of amine at elevated temperature. Since some functional groups are sensitive to high temperature, a variety of activators such as alkali metal halides, metal perchlorates, metal tetrafluoroborates and metaltriflates have been reported to carry out this reaction. However, many of these methods involve the use of expensive and stoichiometric amounts of reagents, suffer from poor regioselectivity and also require extended reaction times. Therefore, the development of a new and efficient protocol for this transformation under mild and more convenient conditions is still needed. On the other hand, use of ionic liquids as alternatives to conventional organic solvents is increasing at a rapid rate in many areas of chemistry, in particular in the area of organic synthesis. It is due to the fact that the ionic liquids provide green chemistry and ecofriendly technologies as they can be recycled many times without loss of efficiency ${ }^{2}$. Ionic liquids have higher boiling points compared to organic solvents which have lower boiling points and this property makes ionic liquids as best alternatives to organic solvents. The bmim $\mathrm{BF}_{4}$ belongs to the class of Ionic liquids which we have used in the current study and found it to be an effective reagent and solvent. By using ionic liquid, high product yields can be obtained, and a reduced amount of waste can be produced in a given reaction. Often the ionic liquid can be recycled and was reused for five runs without any loss of activity. Therefore it leads to a reduction of the costs of the processes. It must be emphasized that reactions in ionic liquids are not difficult to perform and usually require no special apparatus or methodologies. The reactions are often quicker and easier to carry out than in conventional organic solvents.

\section{Results and Discussions}

In this communication, we wish to report the exploition of Ionic liquids, in particular bmim $\mathrm{BF}_{4}$ as an efficient reaction medium for the ring opening of various epoxides with nitrogen nucleophiles under mild and moderate reaction conditions as shown in the schemes 1 .

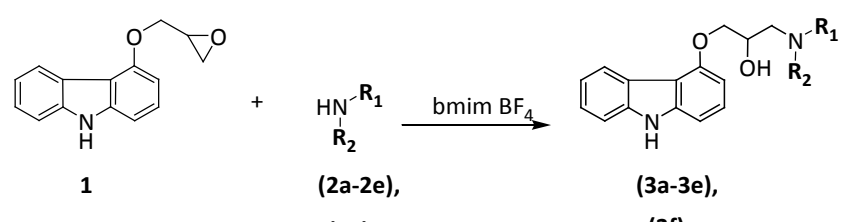

(3a)

(3f)

Scheme 1

In a typical experiment, epoxy, propoxy carbazole and amine derivatives were reacted in presence of bmim $\mathrm{BF}_{4}$, at ambient temperature to obtain the corresponding $\beta$-amino alcohol derivatives and the obtained results were shown in the table 1. In all of the reactions, an equimolar amount of an 
epoxide and amine were mixed, in which a suitable amount of bmim $\mathrm{BF}_{4}$ was added. First, epoxy, propoxy carbazole (1) was subjected to the opening with various amines (2a-e and 3a) in the presence of bmim $\mathrm{BF}_{4}$. The reaction between compound $\mathbf{1}$ and compound 2a was rather fast in the presence of bmim $\mathrm{BF}_{4}$ and the corresponding $\beta$-amino alcohol 3a, was obtained nearly in aquantitative yield (91\%) within 45 minutes at room temperature ( Table 1, entry 1). A somewhat milder reaction between compound $\mathbf{1}$ and compound $\mathbf{2 b}$ took place employing bmim $\mathrm{BF}_{4}$ and compound $\mathbf{3 b}$ was isolated in quantitative yield $(85 \%)$ after 35 minutes at room temperature (Table 1 , entry 2 ). In the case of the reactions between compound $\mathbf{1}$ and the compound 2c, in the presence of bmim $\mathrm{BF}_{4}$ at room temperature obtained compound $3 \mathbf{c}$ in quantitative yield $(83 \%)$ after 50 minutes (Table 1, entry 3). On the other hand, the ring opening reactions of compound $\mathbf{1}$ with the secondary amines 2d and 2e were sluggish and had to be heated at $60^{\circ} \mathrm{C}$ for 120 minutes in the presence of bmim $\mathrm{BF}_{4}$ (Table 1,entry 4 and 5). Compounds 3d, $3 \mathbf{e}$ were obtained in $85 \%$ and $79 \%$ respectively. Reaction of compound $\mathbf{1}$ and compound $\mathbf{3 a}$ was performed at $60^{\circ} \mathrm{C}$ for 180 minutes in the presence of bmim $\mathrm{BF}_{4}$ compound $\mathbf{3 f}$ was isolated in $78 \%$ yield (Table 2, entry $1)$.

Table 1. Reaction of Compound with various amines

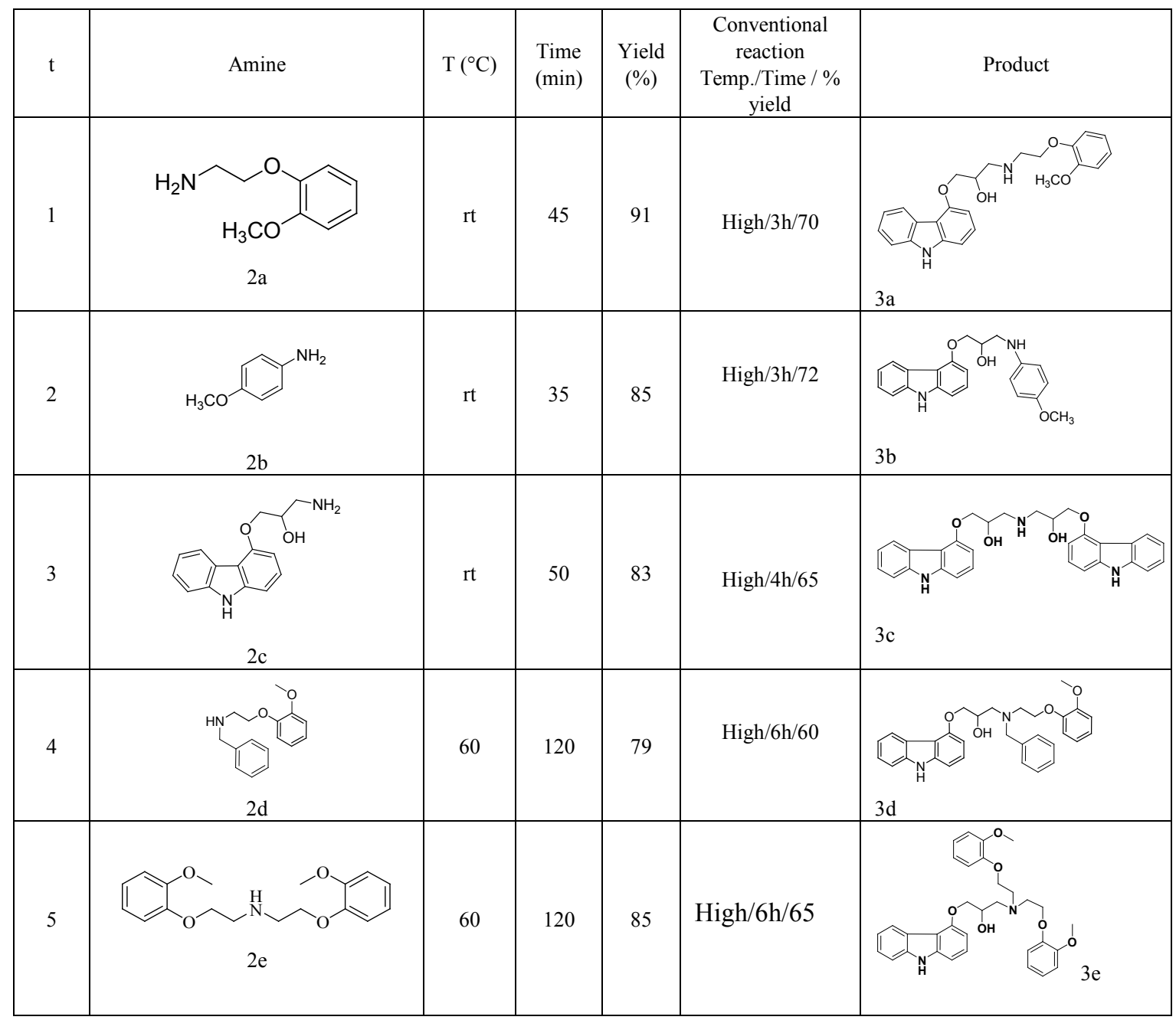

Table.2. Reaction of $3 \mathrm{a}$ ad as a hindered amine

\begin{tabular}{|c|c|c|c|c|c|c|}
\hline $\begin{array}{c}\text { Entr } \\
\mathrm{y}\end{array}$ & Amine & $\begin{array}{c}\mathrm{T} \\
\left({ }^{\circ} \mathrm{C}\right)\end{array}$ & $\begin{array}{c}\text { Time } \\
(\mathrm{min})\end{array}$ & $\begin{array}{c}\text { Yield } \\
(\%)\end{array}$ & $\begin{array}{c}\text { Conventional reaction } \\
\text { Temp./Time / \% yield }\end{array}$ & Product \\
\hline 1 & & & & & & \\
\hline
\end{tabular}

The spectra (IR, NMR and Mass) for compound 3c are given below as a typical example. Spectra for all the products are 
given in the enclosed supplementary data (Figures 1-14).

IR spectrum of $3 \mathrm{c}$

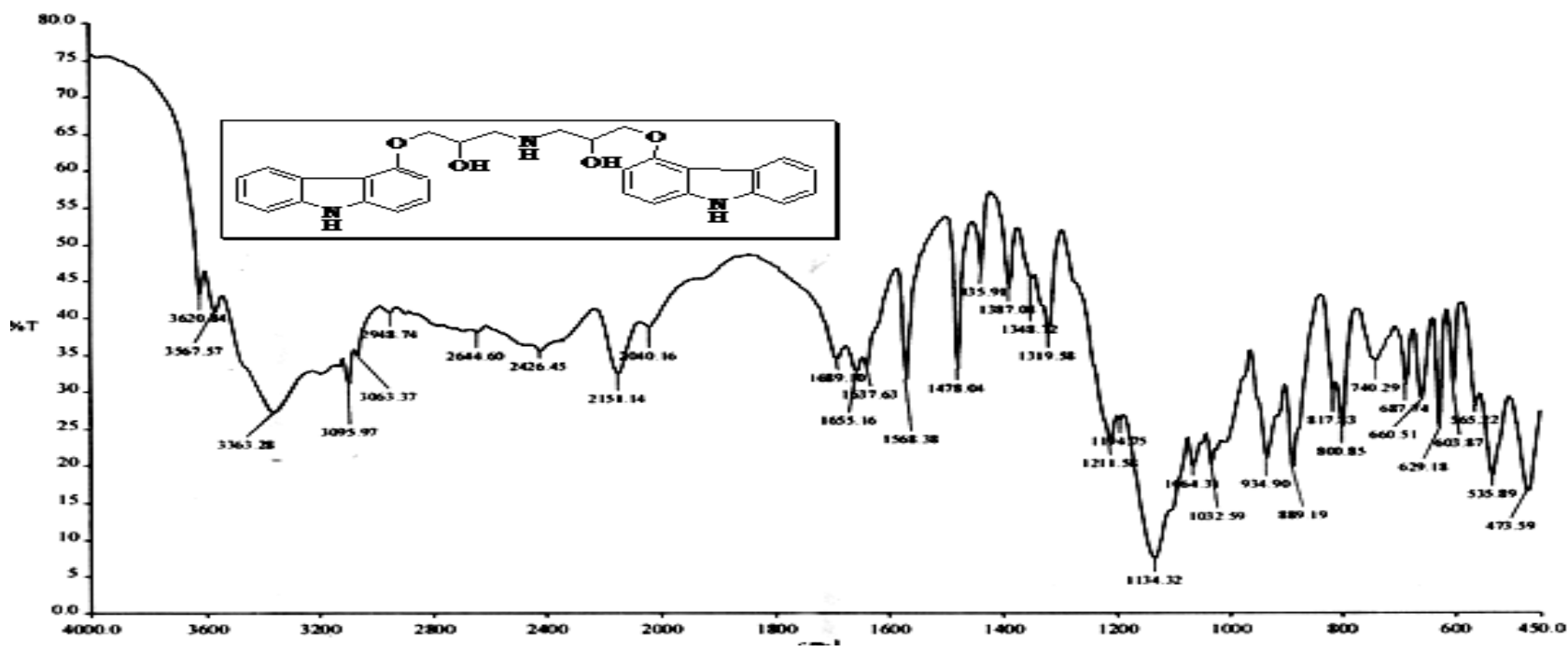

1HNMR spectrum of $3 \mathrm{c}$

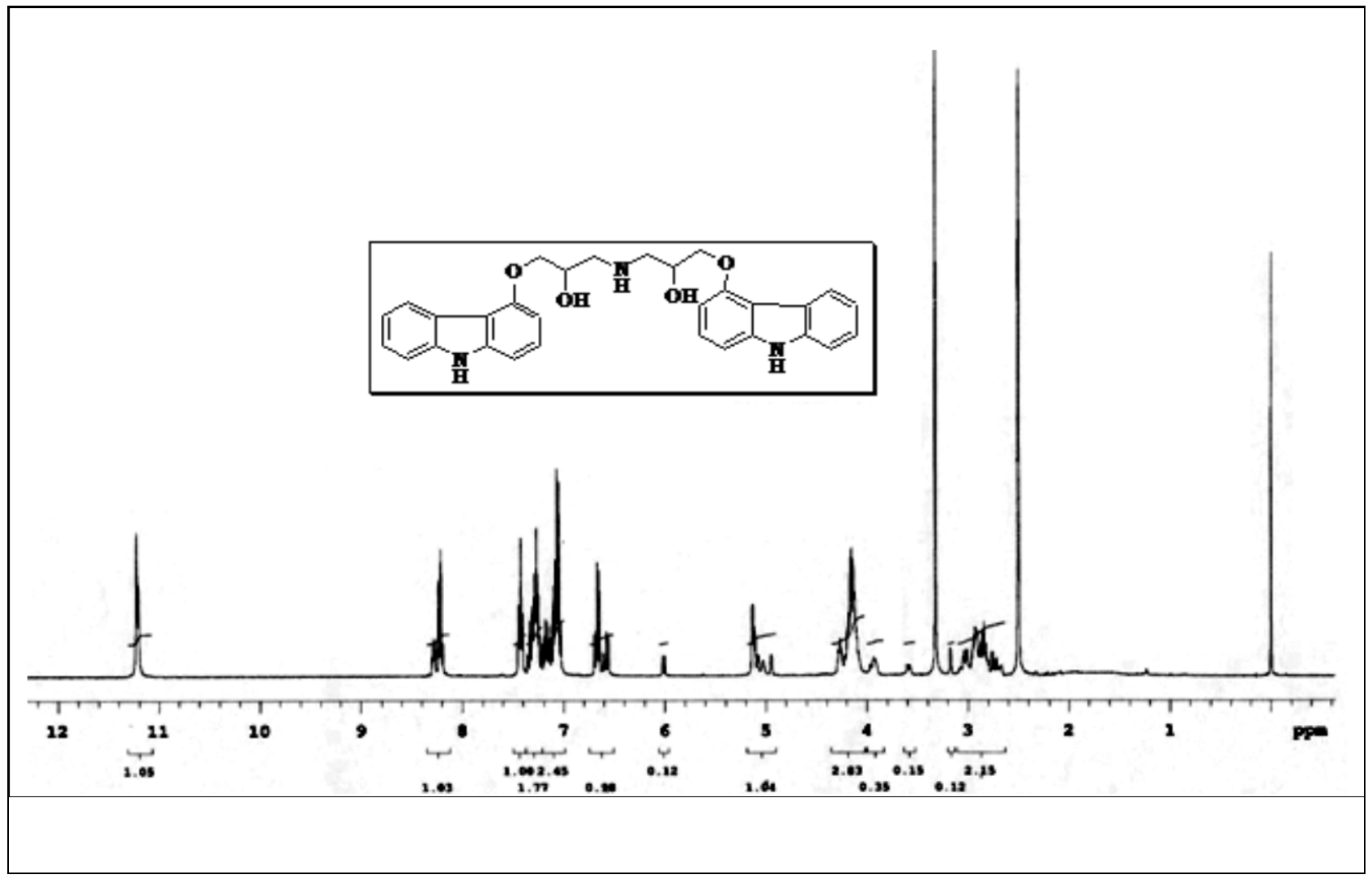


Mass spectrum of $3 \mathrm{c}$

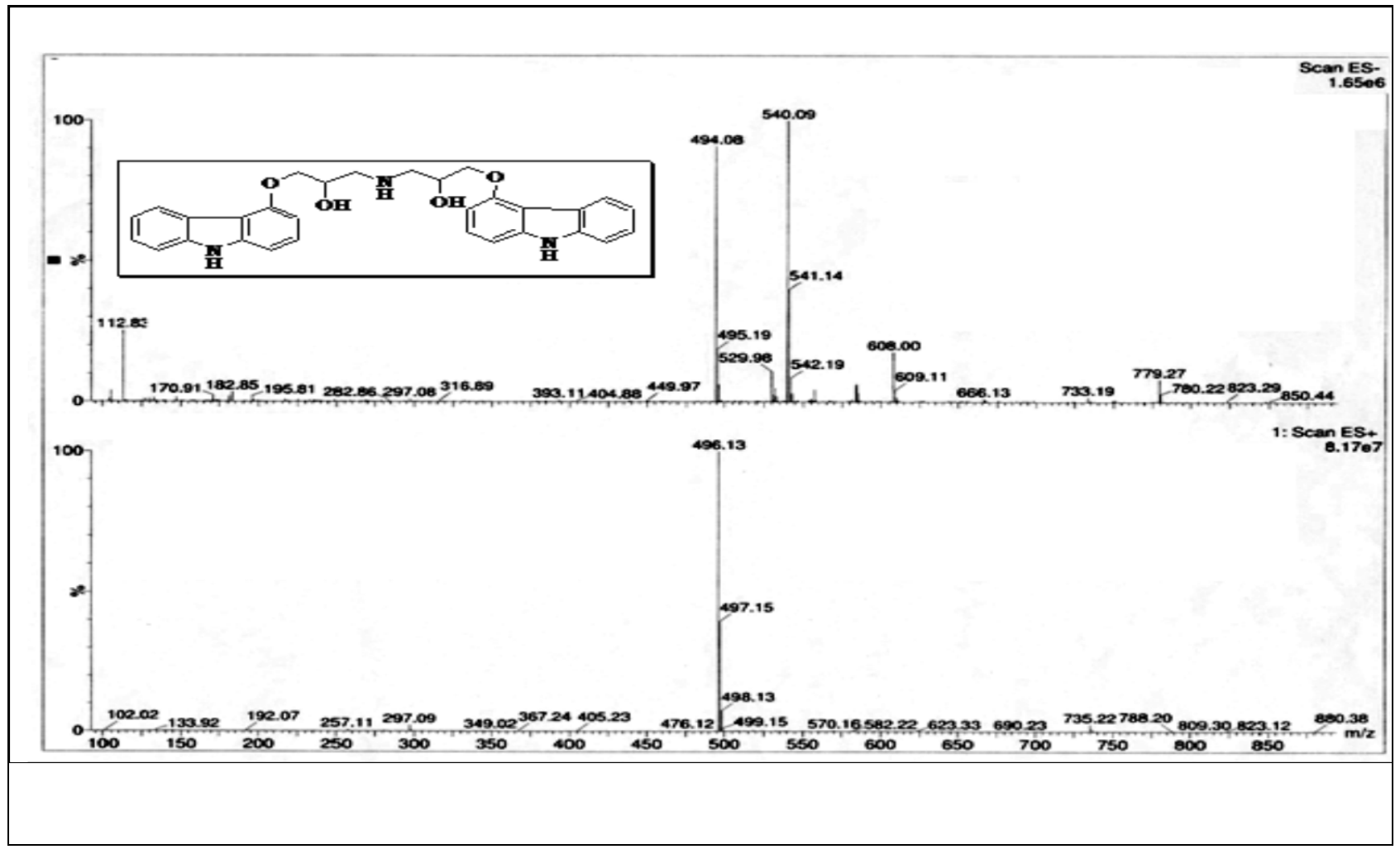

\section{Experimental Section}

FT-IR spectra were recorded as $\mathrm{KBr}$ pellet on Nicolet 380 FT-IR instrument (Model Thermo Electron Corporation-Spectrum One). ${ }^{1} \mathrm{H}$ spectra were recorded on Varian 300 and $400 \mathrm{MHz}$ spectrometers using $\mathrm{CDCl}_{3}, \mathrm{DMSO}_{-} \mathrm{d}_{6}$ as solvents, and tetra methyl silane (TMS) as internal standard. Mass spectra were recorded on Agilent triple quadrupole mass spectrometer equipped with turbo ion spray interface at $375^{\circ} \mathrm{C}$. All the organic extracts were dried over sodium sulfate after work-up. The dry reactions were carried out under nitrogen atmosphere with magnetic/mechanical stirring. Unless otherwise mentioned, all the solvents and reagents used were of LR grade. TLC was performed on precoated silica-gel plates, which were visualized using UV light and sulphuric acid/ethanol (5:95) charring.

\subsection{General Procedure}

To a mixture of epoxide $(1 \mathrm{~mol})$ and amine $(1 \mathrm{~mol})$ was added the bmim $\mathrm{BF}_{4}(10 \mathrm{~mol} \%)$. The resulting reaction mixture was stirred at ambient temperature for a specified period (Table1). The progress of the reaction was monitored by TLC. After complete conversion of the starting material, as indicated by TLC, the product was extracted with di ethyl ether, followed by drying at $80^{\circ} \mathrm{C}$ under reduced pressure to afford the corresponding pure $\beta$-amino alcohol derivatives in excellent yields. All the products were confirmed by their ${ }^{1} \mathrm{HNMR}$, IR and Mass spectrometry and compared with literature data.

\subsection{Spectral Data for 3a}

Compound 3a: IR (Kbr): 3344 cm-1 (-OH); 1H NMR (CDCl3; $400 \mathrm{MHz}): \delta 8.5$ (m, 2H, -carbazole), 7.4 (m, 4H, -Aromatic), 7.1 (m, 5H, -Carbazole), 6.4 (d, 1H, J=6.8 -carbazole), 4.1 (m, 5H, -CH2-CH-CH2), 3.85 (s, 3H, -OCH3), 2.92 (m, 2H, -CH2), 2.9 (m, 2H, -CH2), 2.1 (bs, -NH); 13C NMR (100 MHz, DMSO) (Fig.2.6): $\delta$ 48.48, 52.13, 54.95, 68.17, $68.69,70.21,100.13,103.63,109.71,111.93,112.21,114.25,118.42,120.76,121.49,122.17,124.26,126.04,139.29,141.53$, 148.15, 149.71, 155.11; MS: m/z (M+1) 407. HRMS: m/z calculated for C24H26N2O4, 406.19 Found: C24H26N2O4, 406.168

Compound 3b:IR (KBr, cm-1): 3391, 3292, 2929, 1513, 1259, 1105, 717. 1H NMR (400 MHz, DMSO-d6): $\delta 11.22$ (s, 
$1 \mathrm{H}), 8.25(\mathrm{~d}, \mathrm{~J}=7.6 \mathrm{~Hz}, 1 \mathrm{H}), 7.46(\mathrm{~d}, \mathrm{~J}=7.6 \mathrm{~Hz}, 1 \mathrm{H}), 7.37-7.27(\mathrm{~m}, 2 \mathrm{H}), 7.16(\mathrm{t}, \mathrm{J}=7.0 \mathrm{~Hz}, 1 \mathrm{H}), 7.08(\mathrm{~d}, \mathrm{~J}=8.0 \mathrm{~Hz}$, $1 \mathrm{H}), 6.72-6.66(\mathrm{~m}, 5 \mathrm{H}), 5.28(\mathrm{~s}, 1 \mathrm{H}), 5.20(\mathrm{t}, \mathrm{J}=4.0 \mathrm{~Hz}, 1 \mathrm{H}), 4.27-4.16(\mathrm{~m}, 3 \mathrm{H}), 3.61(\mathrm{~s}, 3 \mathrm{H}), 3.43-3.35(\mathrm{~m}, 1 \mathrm{H})$, 3.24-3.16 (m, 1H). 13C NMR (100 MHz, DMSO-d6): 154.9, 150.7, 143.0, 141.0, 138.9, 126.4, 124.5, 122.4, 121.7, 118.5, 114.6, 113.2, 110.9, 110.3, 103.8, 100.4, 70.2, 67.8, 55.3, 47.4. MS (m/z): 363 (M+1). HRMS. m/z Calculated for $\mathrm{C} 22 \mathrm{H} 22 \mathrm{~N} 2 \mathrm{O} 3362.16$ Found C22H22N2O3 362.1459

Compound 3c:IR (Kbr): 3620, 3567 and $3363 \mathrm{~cm}-1(-\mathrm{NH}), 3095$ and $3063 \mathrm{~cm}-1(-\mathrm{OH})$;

1H NMR(300 MHz, dmso): $\delta 11.2$ (s, 2H, -NH), 8.2 (m, 2H, -Aromatic), 7.5 (m, 2H, -Aromatic), 7.3 (m, 4H, -Aromatic), 7.2 (m, 4H, -Aromatic), 6.6 (m, 2H, -Aromatic), $5.2(\mathrm{~m}, 2 \mathrm{H},-\mathrm{OH}), 4.2$ (m, 4H, -OCH3), 4.0 (m, 2H, -CH), 2.8 (m, 4H, -CH2); MS: m/z (M-1) 494 and (M+1) 496. HRMS m/z calculated: for C30H29N3O4 495.58 Found:C30H29N3O4 495.5689

Compound 3d:IR (Kbr): $3401 \mathrm{~cm}-1(-\mathrm{OH}), 3059 \mathrm{~cm}-1$ (-CH aromatic);

1H NMR (300 MHz, CdCl3) : $\delta 8.2(\mathrm{~d}, 1 \mathrm{H}, \mathrm{J}=7.8$, -Aromatic), 8.0 (s, 1H, -NH), 7.5-7.2 (m, 9H, -Aromatic), 6.8 (m, 5H, -Aromatic), 6.6 (d, 1H, J=8.0, -Aromatic), 4.2 (m, 4H, -OCH2), 4.1 (m, 1H, -CH), 3.9 (m, 6H, -NCH2), 3.0 (m, 3H, -OCH2), 1.5 (s, 1H, -OH); MS: m/z (M+1) 497. HRMS m/z C31H32N2O4 for 496.61 Found C31H32N2O4 496.5891

Compound 3e:IR (Kbr): $3064 \mathrm{~cm}-1$ (-CH Aromatic), $2838 \mathrm{~cm}-1$ (-OCH3);

H1NMR (400 MHz, DMSO-d6/TMS ): $\delta 7.8$ (m, 2H, -tosyl); 7.5 (m, 2H, -tosyl), 6.9 (m, 4H, -Aromatic), 4.3 (m, 2H, -OCH2), $4.1(\mathrm{~m}, 2 \mathrm{H},-\mathrm{CH} 2), 3.7(\mathrm{~s}, 3 \mathrm{H},-\mathrm{OCH} 3), 2.4(\mathrm{~s}, 3 \mathrm{H},-\mathrm{CH} 3) ; \mathrm{MS}: \mathrm{m} / \mathrm{z}(\mathrm{M}+1)$ 323. HRMS m/z calculated for C33H36N2O6: 556.66 Found C33H36N2O6 : 556.6495

Compound 3f:IR (Kbr): $3613 \mathrm{~cm}-1$ and $3530 \mathrm{~cm}-1(-\mathrm{NH}), 3461 \mathrm{~cm}-1$ and $3400 \mathrm{~cm}-1(-\mathrm{OH})$;

1H NMR(300 MHz, dmso): $\delta 11.2(\mathrm{~s}, 2 \mathrm{H},-\mathrm{NH}), 8.2$ (m, 2H, -Aromatic), 7.5 (m, 2H, -Aromatic), 7.3 (m, 8H, -Aromatic), $6.8(\mathrm{~m}, 2 \mathrm{H},-$ Aromatic), $6.6(\mathrm{~m}, 4 \mathrm{H},-$ Aromatic), 5.1(s, 2H, -OH), 4.2(m, 8H, -CH2), 3.9(m, 2H, -CH), 3.6(s, 3H, -OCH3); MS: $\mathrm{m} / \mathrm{z}$ (M) 645.HRMS m/z calculated for C39H39N3O6 645.76 Found C39H39N3O6 645.7496

\section{Conclusions}

In conclusion it has been demonstrated that ionic liquids can be used for the ring opening of epoxides with amines. Ionic liquid can be recycled several times. The details of experimental and spectral data for other compounds are available in the supplementary data.

\section{Appendix - Supplementary Data}

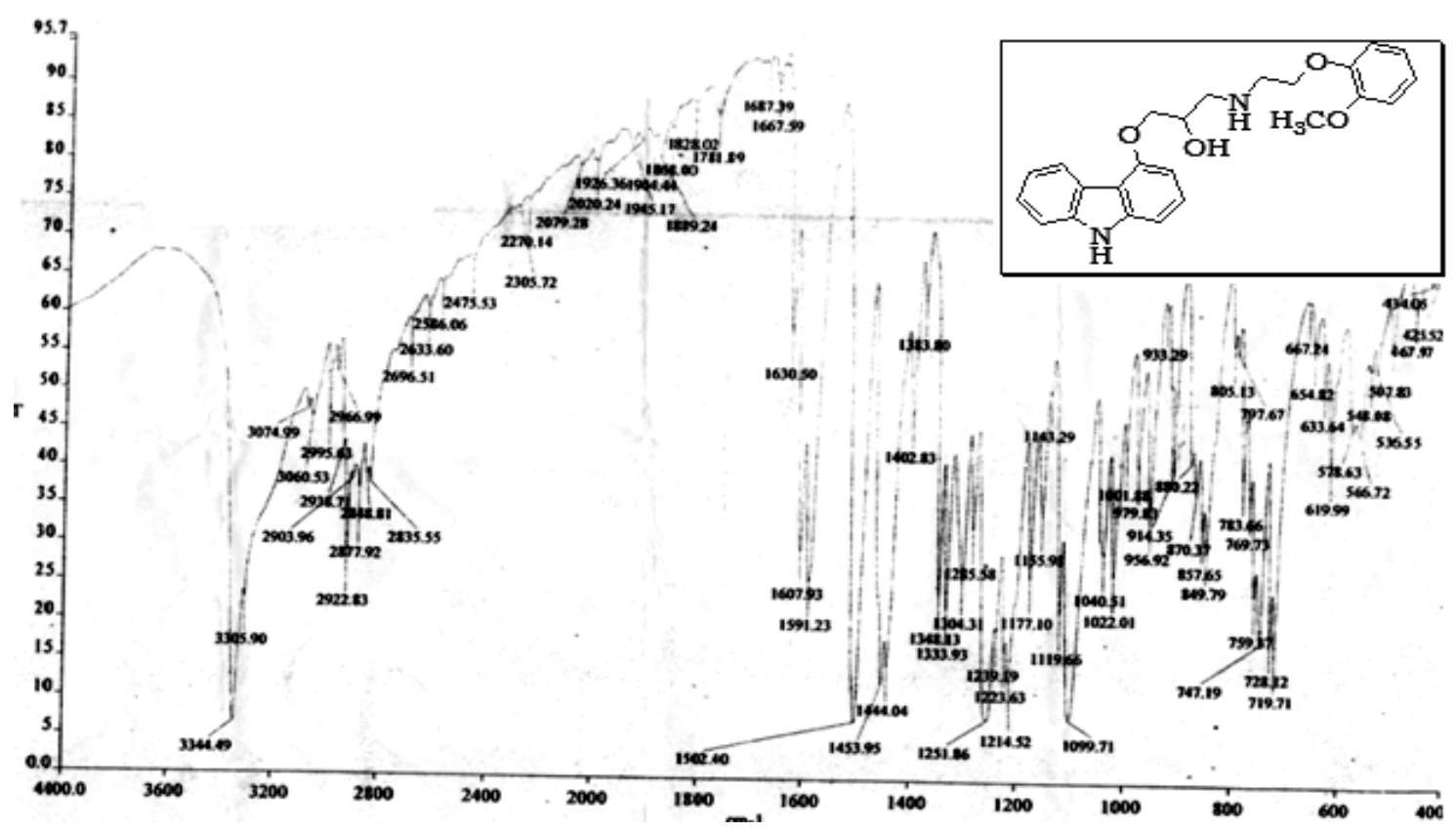

Figure 1. (3a) IR 


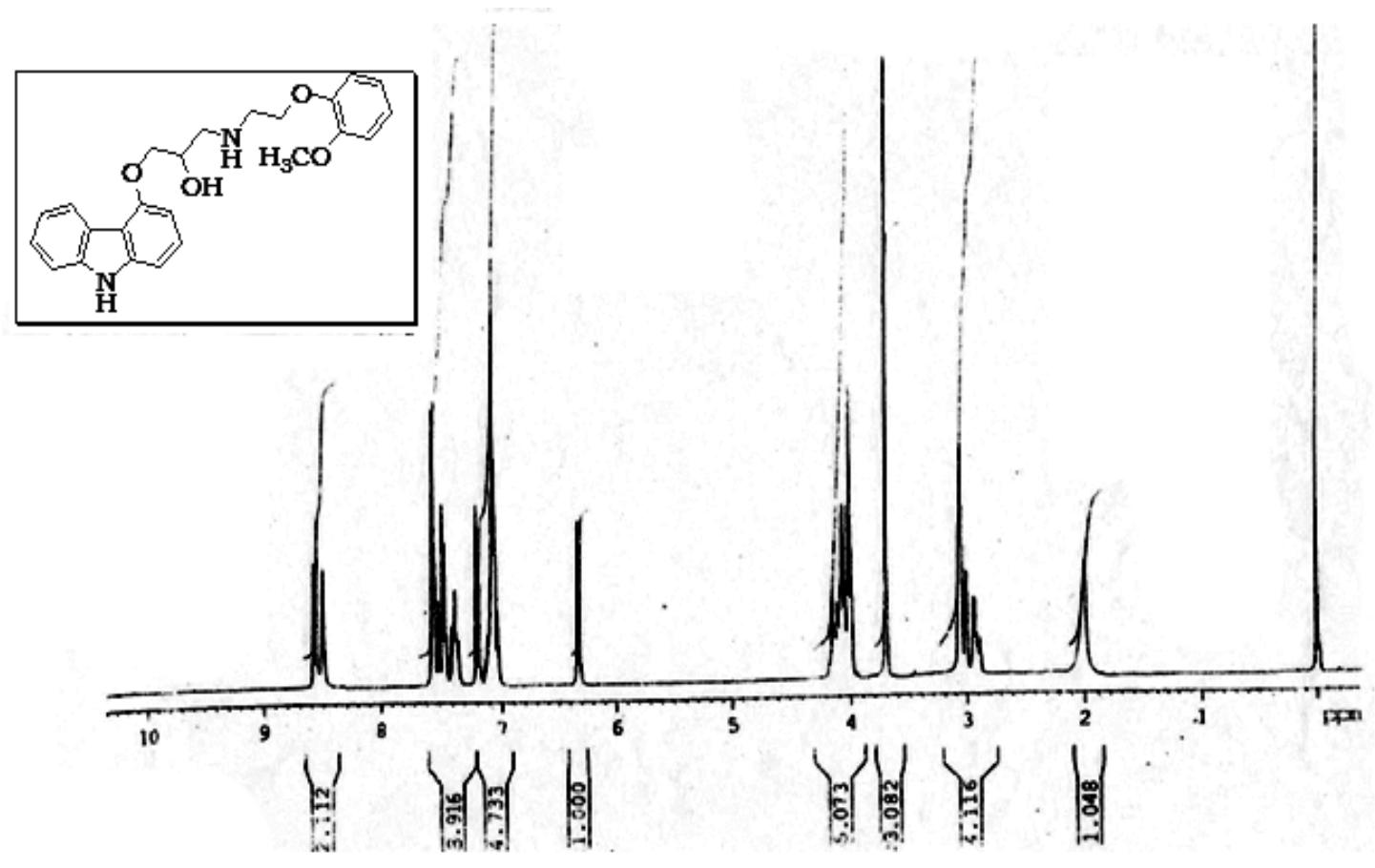

Figure 2. (3a)1HNMR

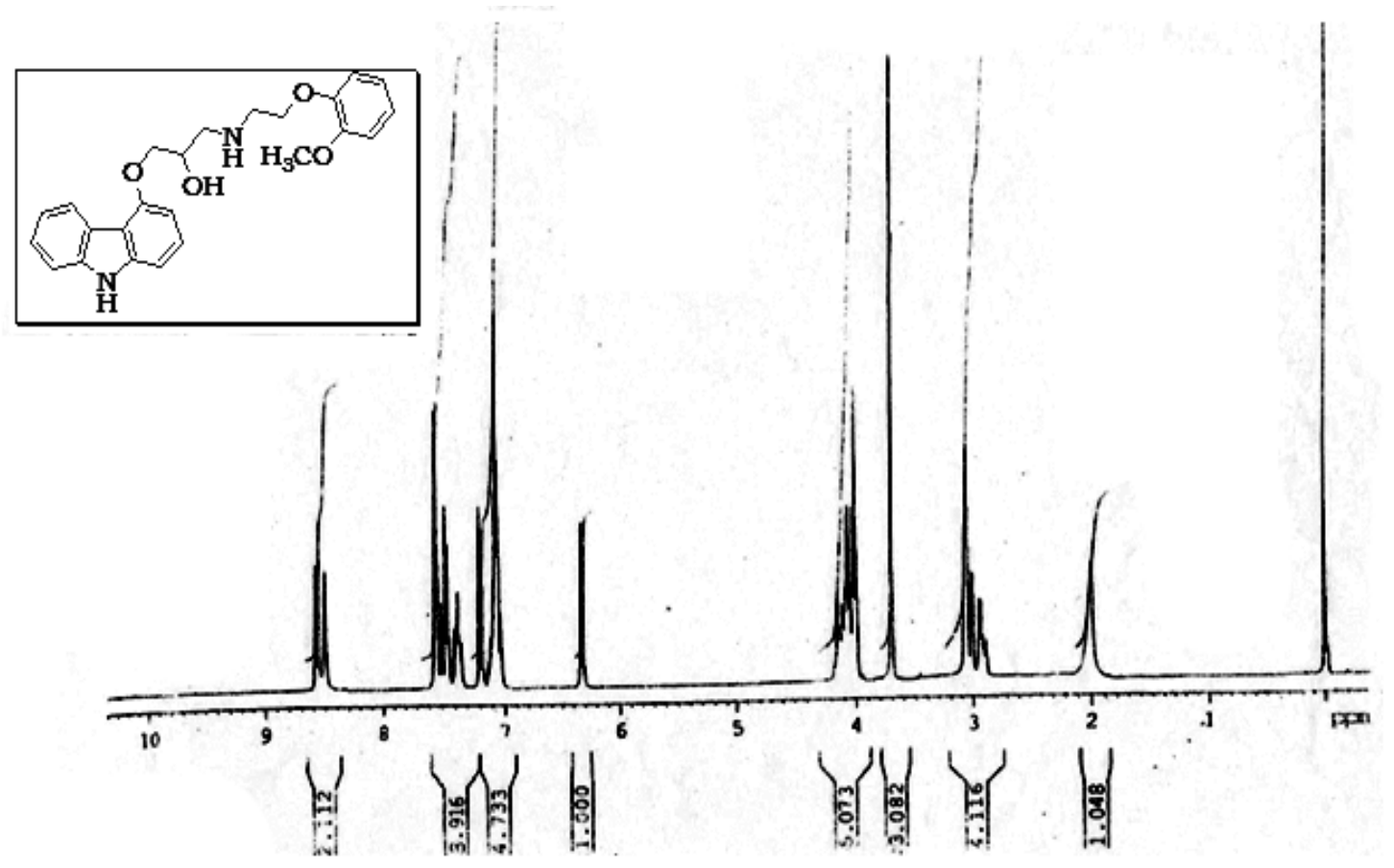

Figure 3. (3a) $13 \mathrm{CNMR}$ 

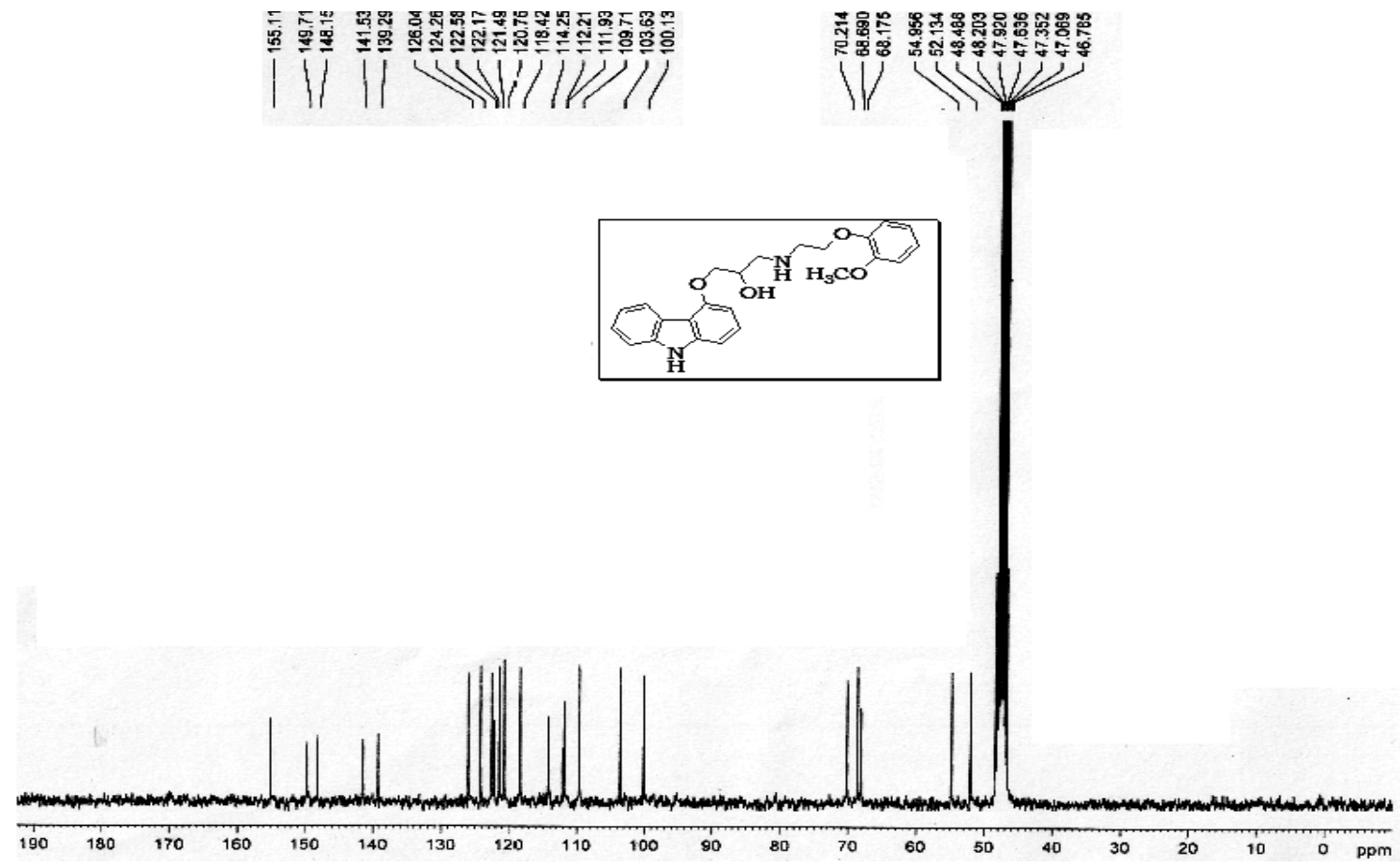

Figure 4. (3b) IR

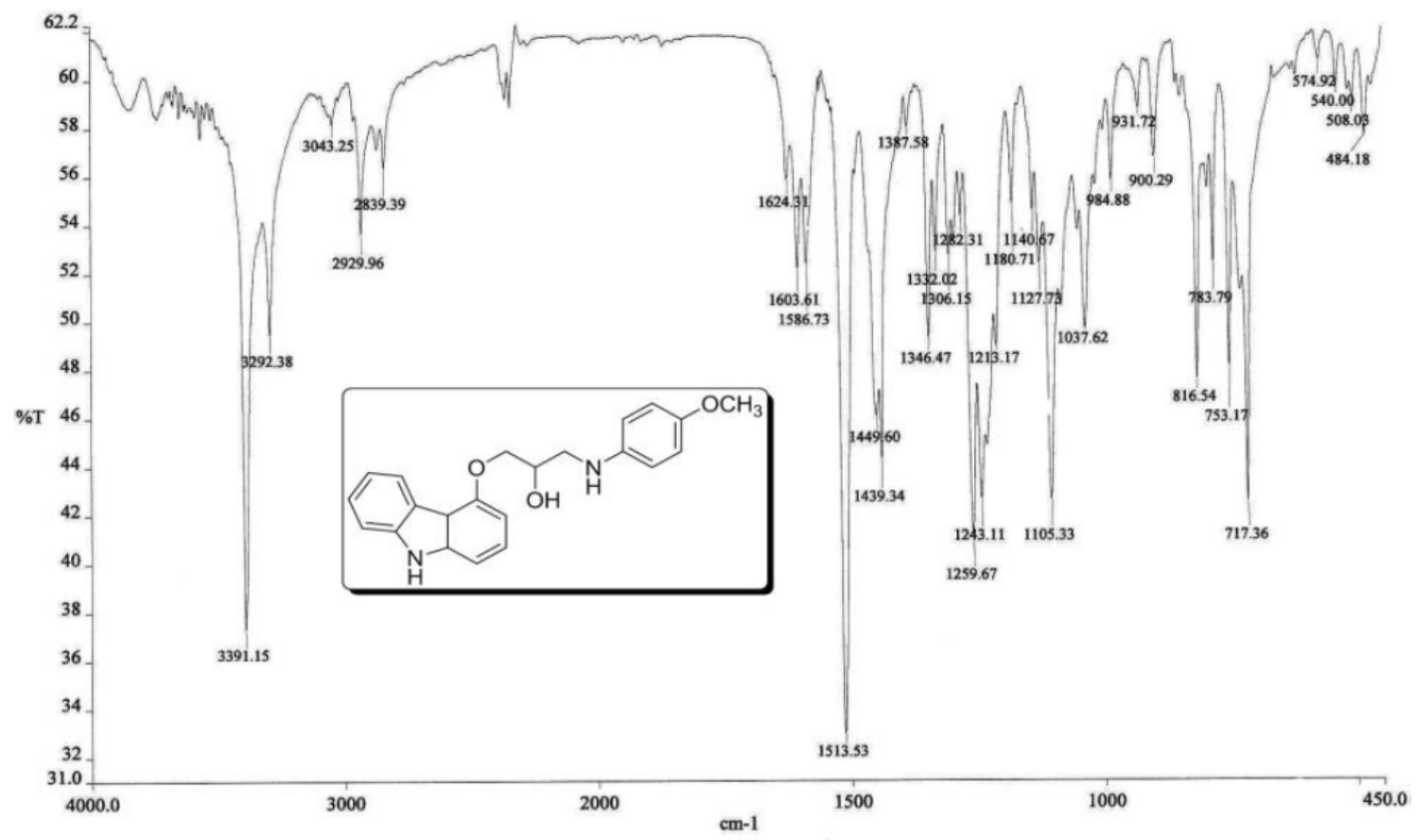

Figure 5. (3a) Mass 


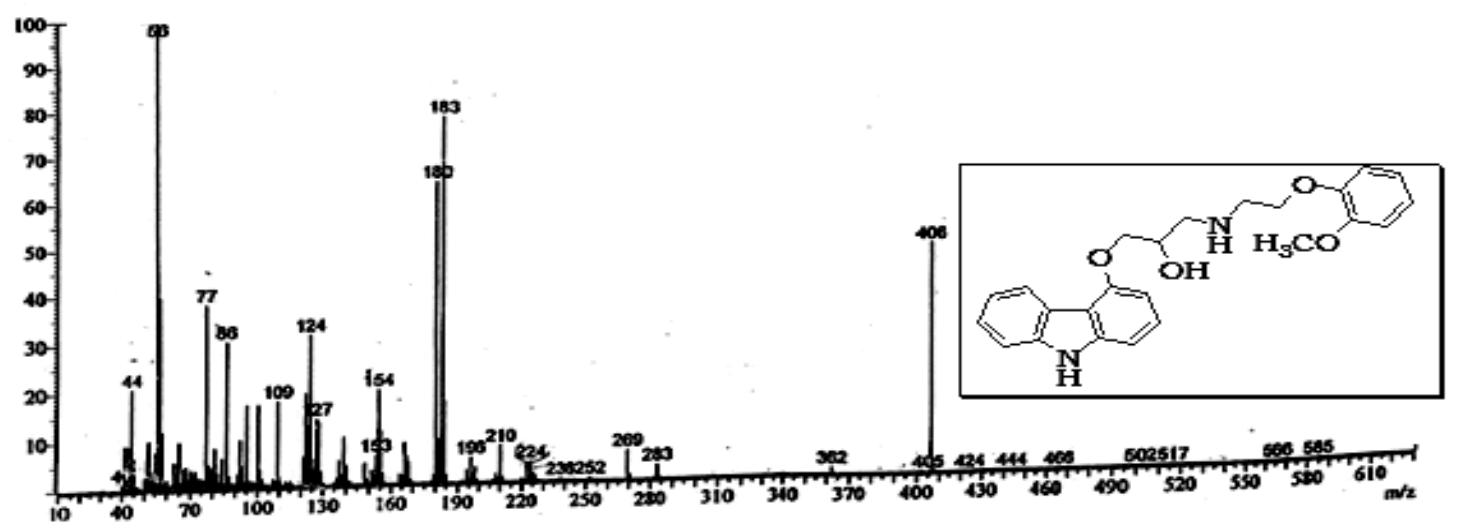

Figure 6. (3b) 1HNMR

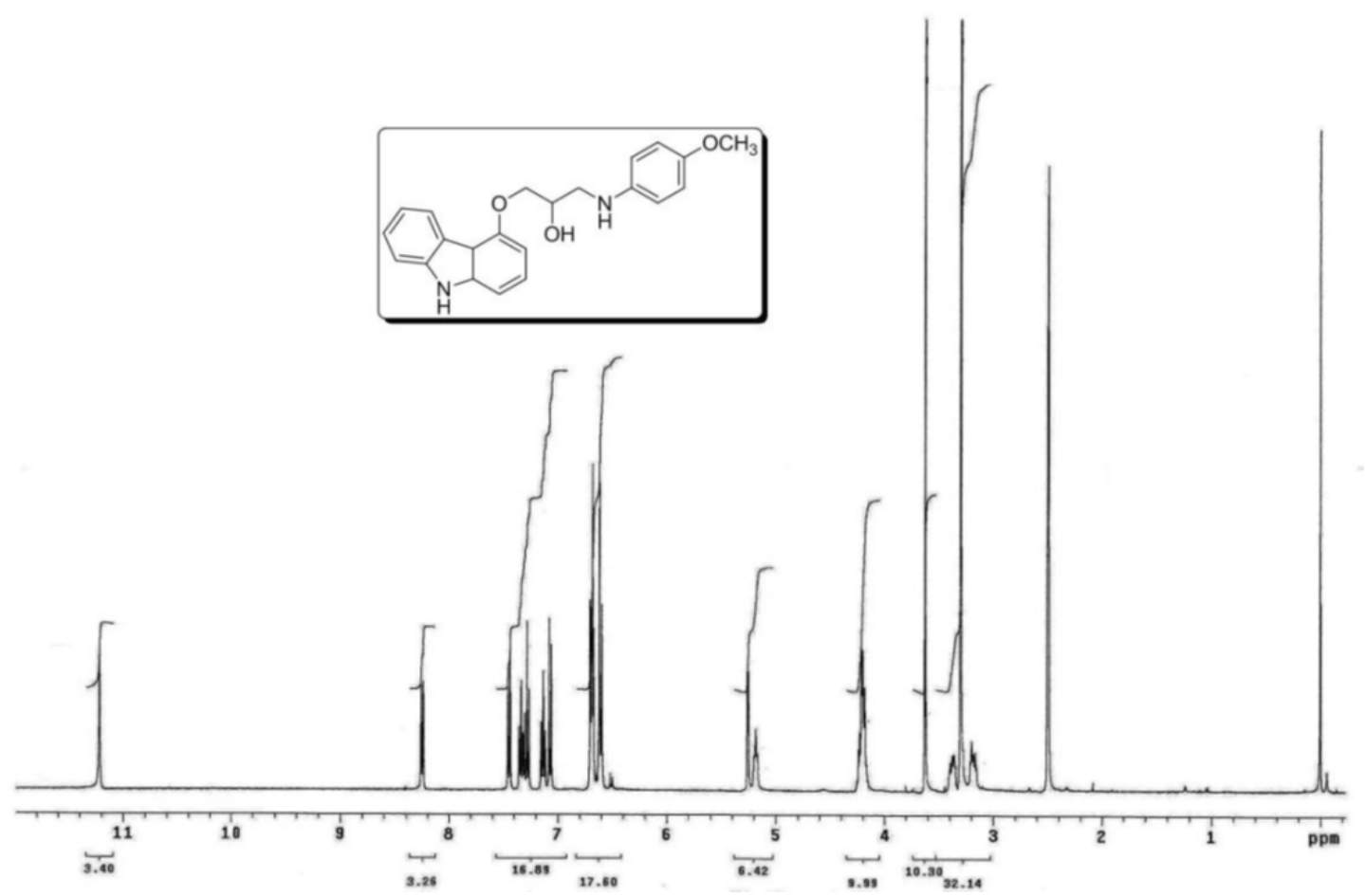

Figure 7. (3b) Mass 


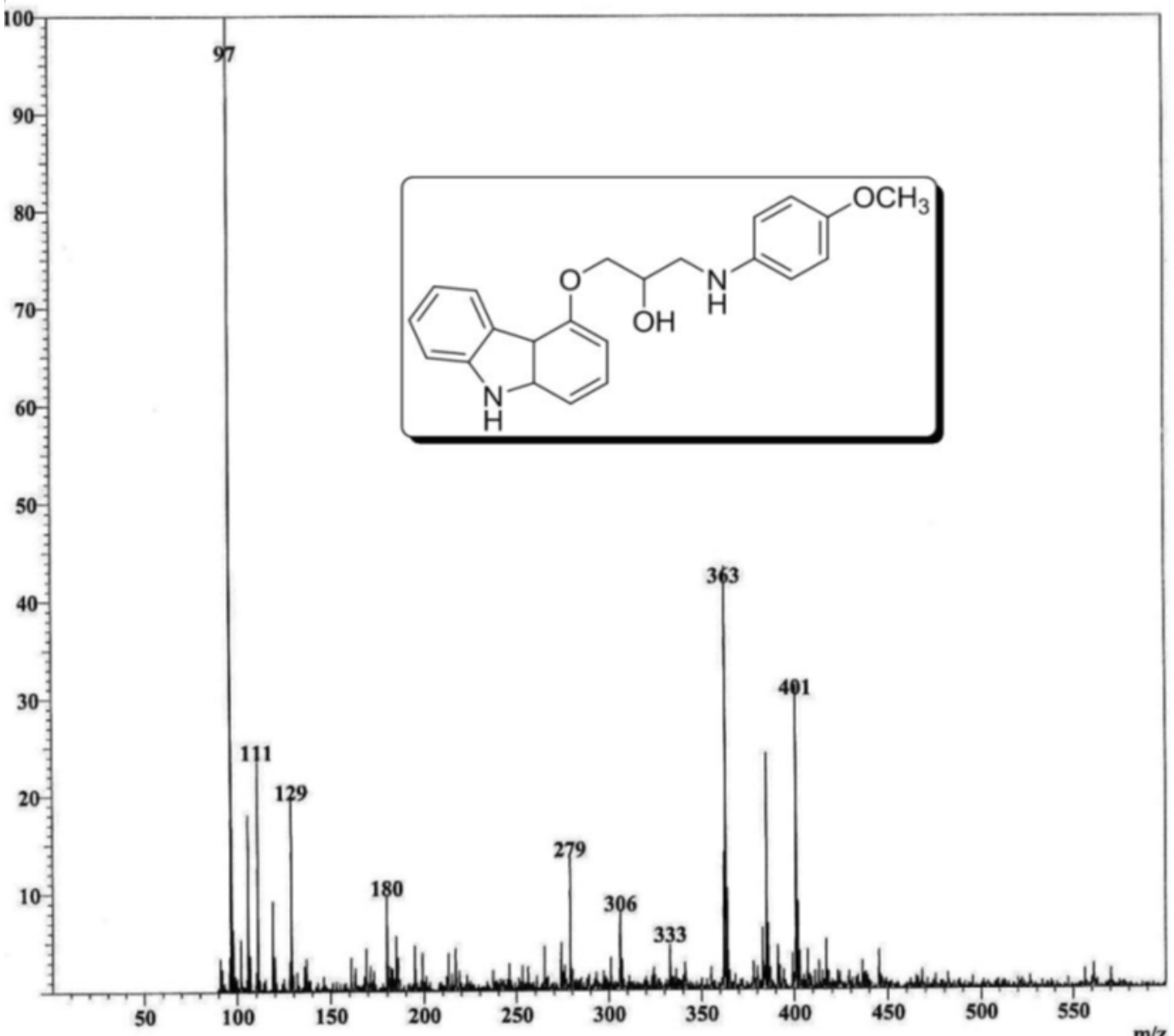

Figure 8. (3c) IR

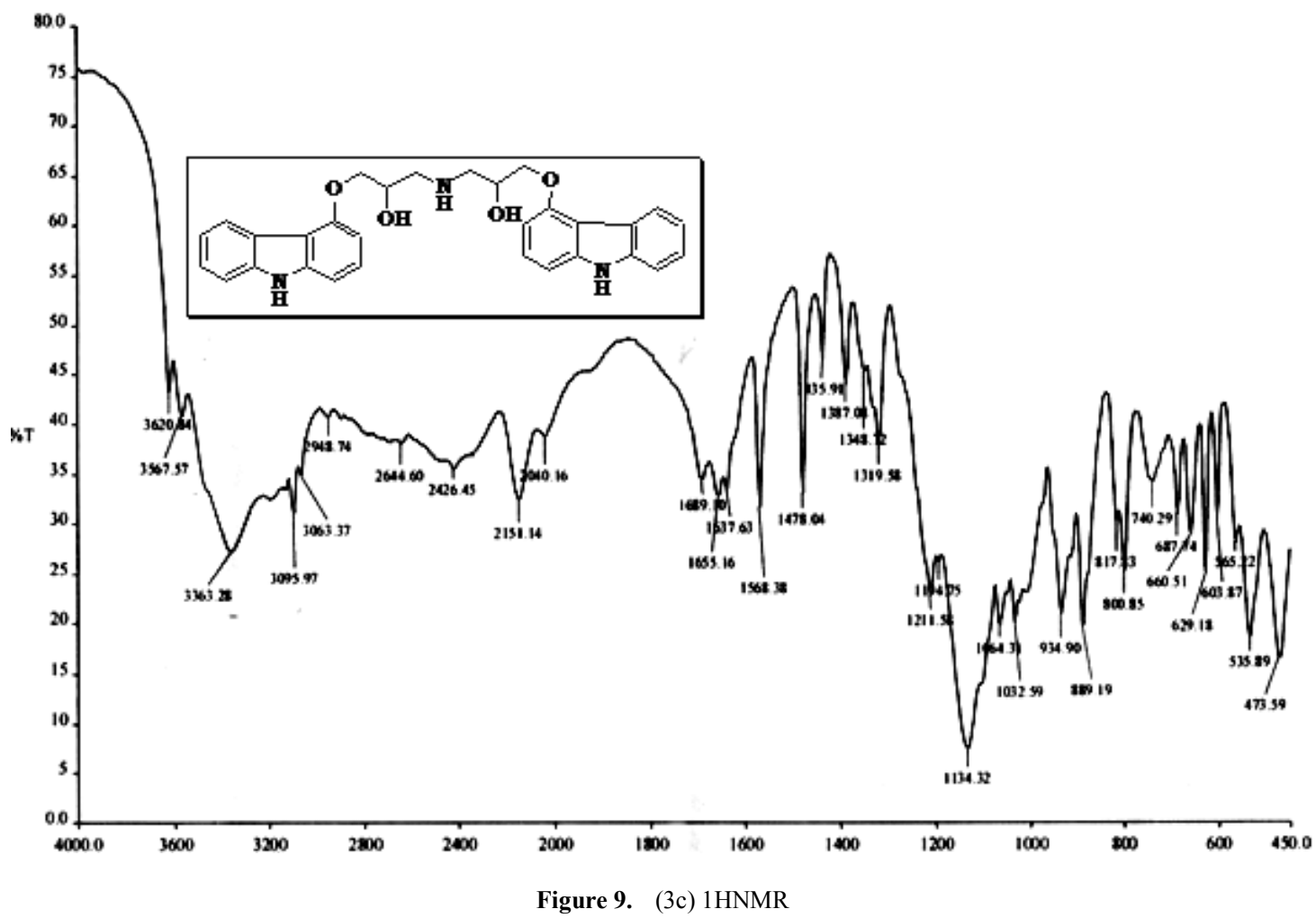




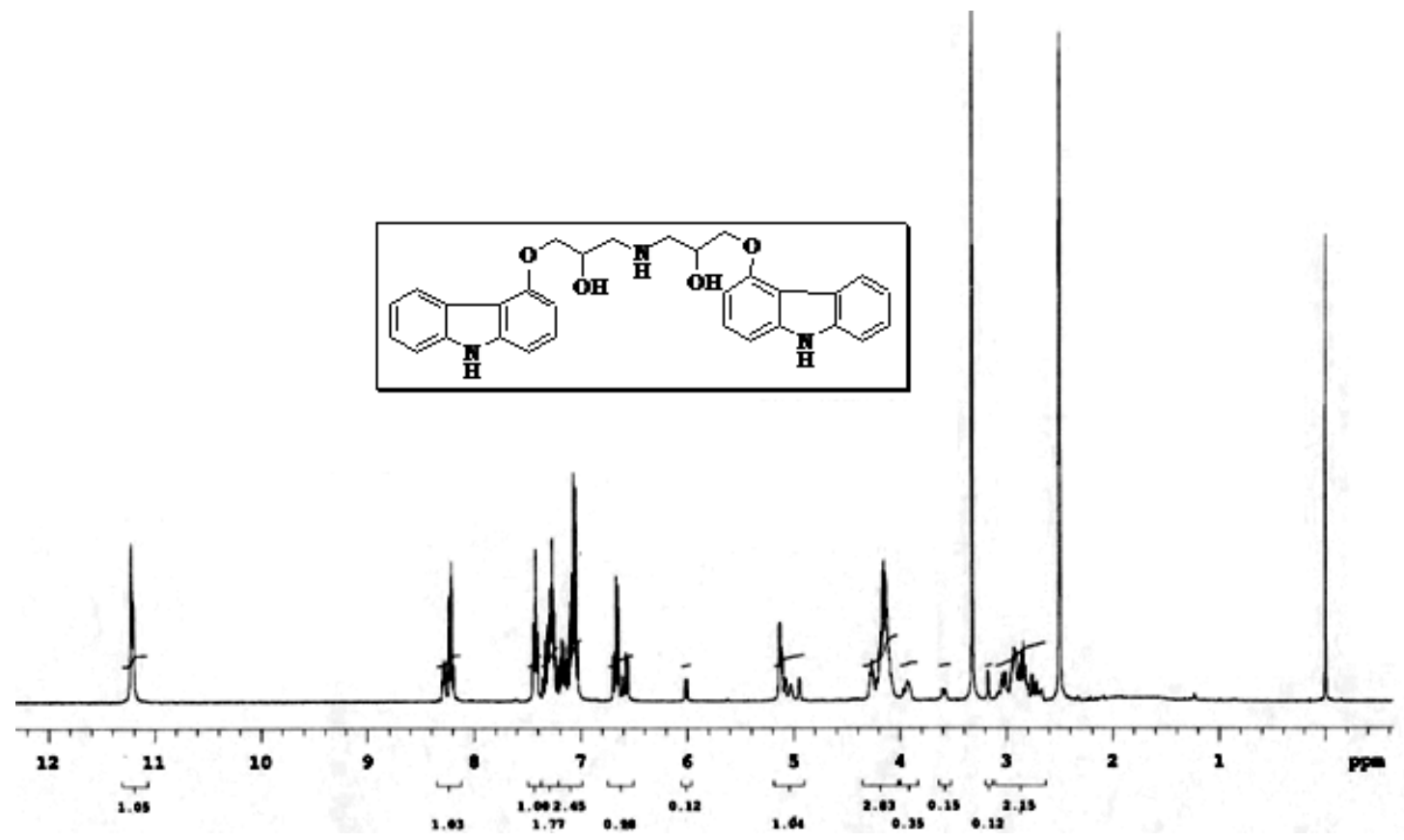

Figure 10. (3c) Mass

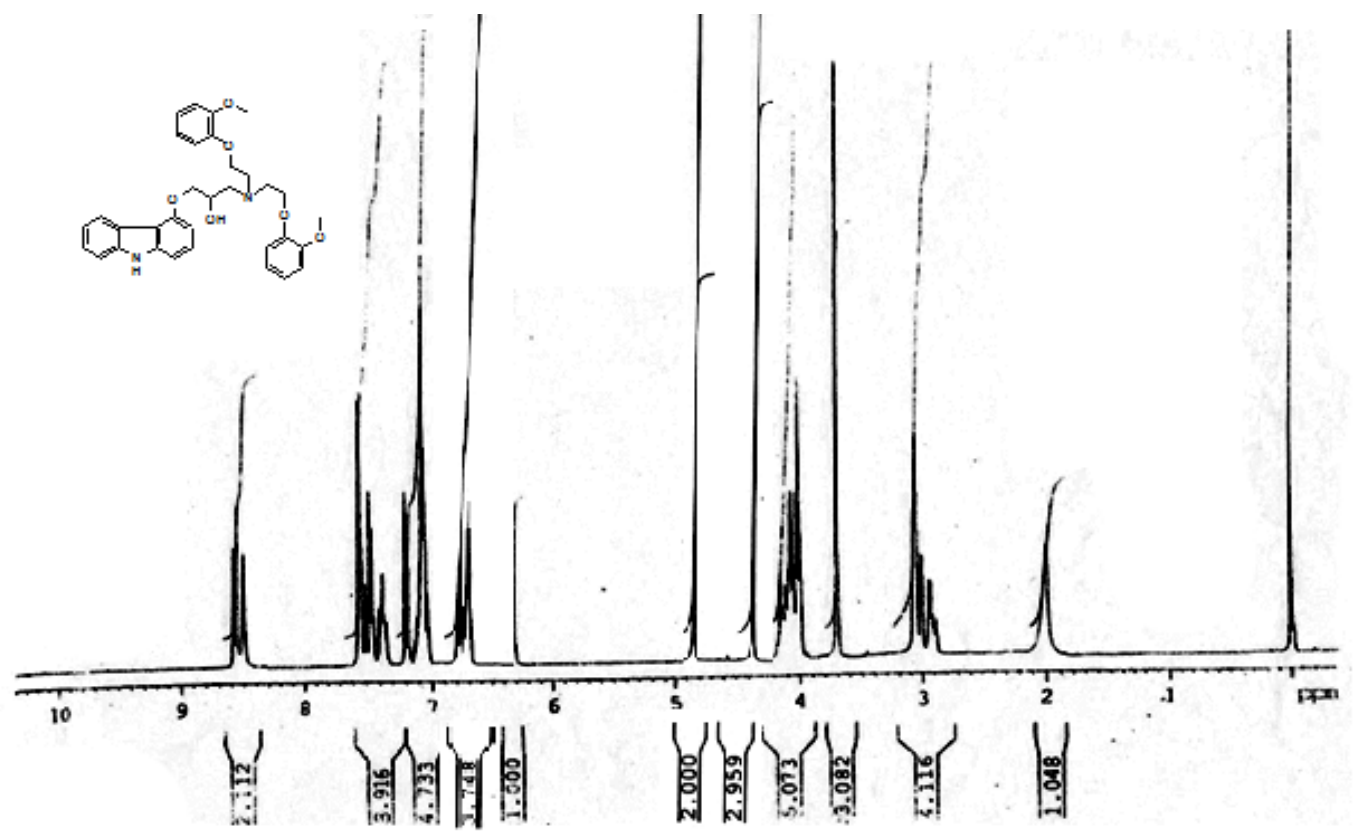

Figure11. (3e) 1HNMR 


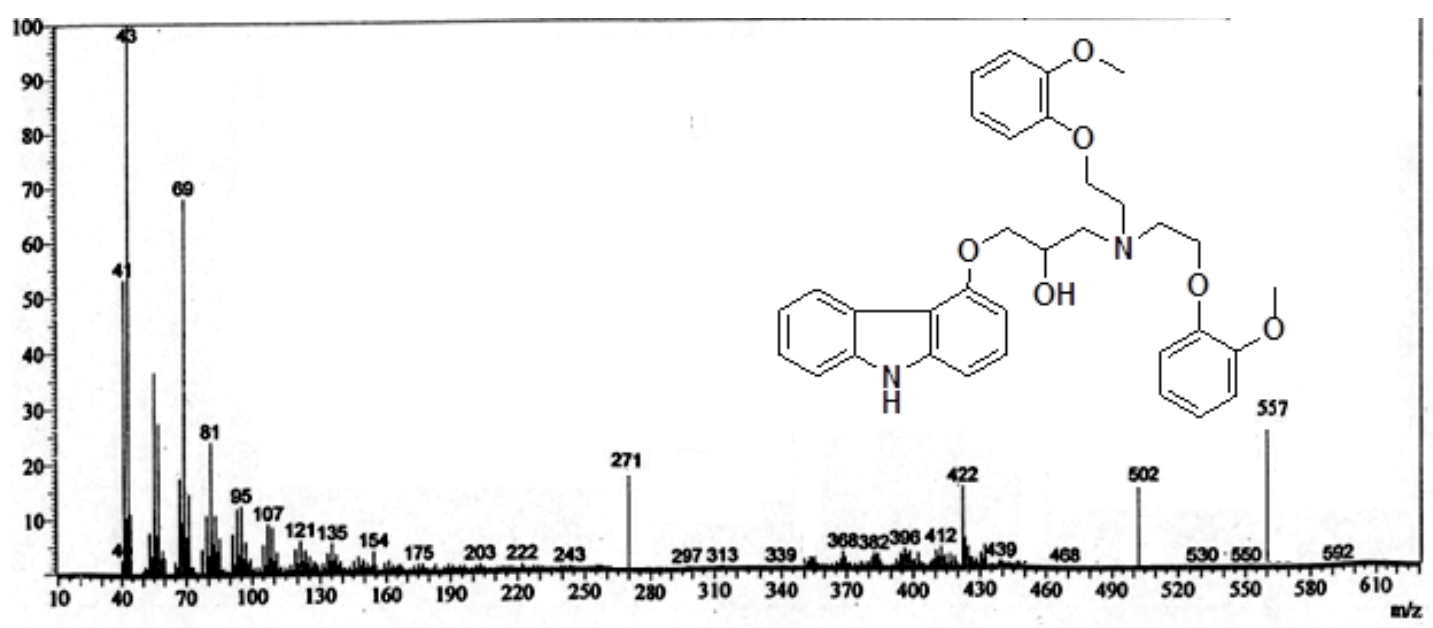

Figure 12. (3e) Mass

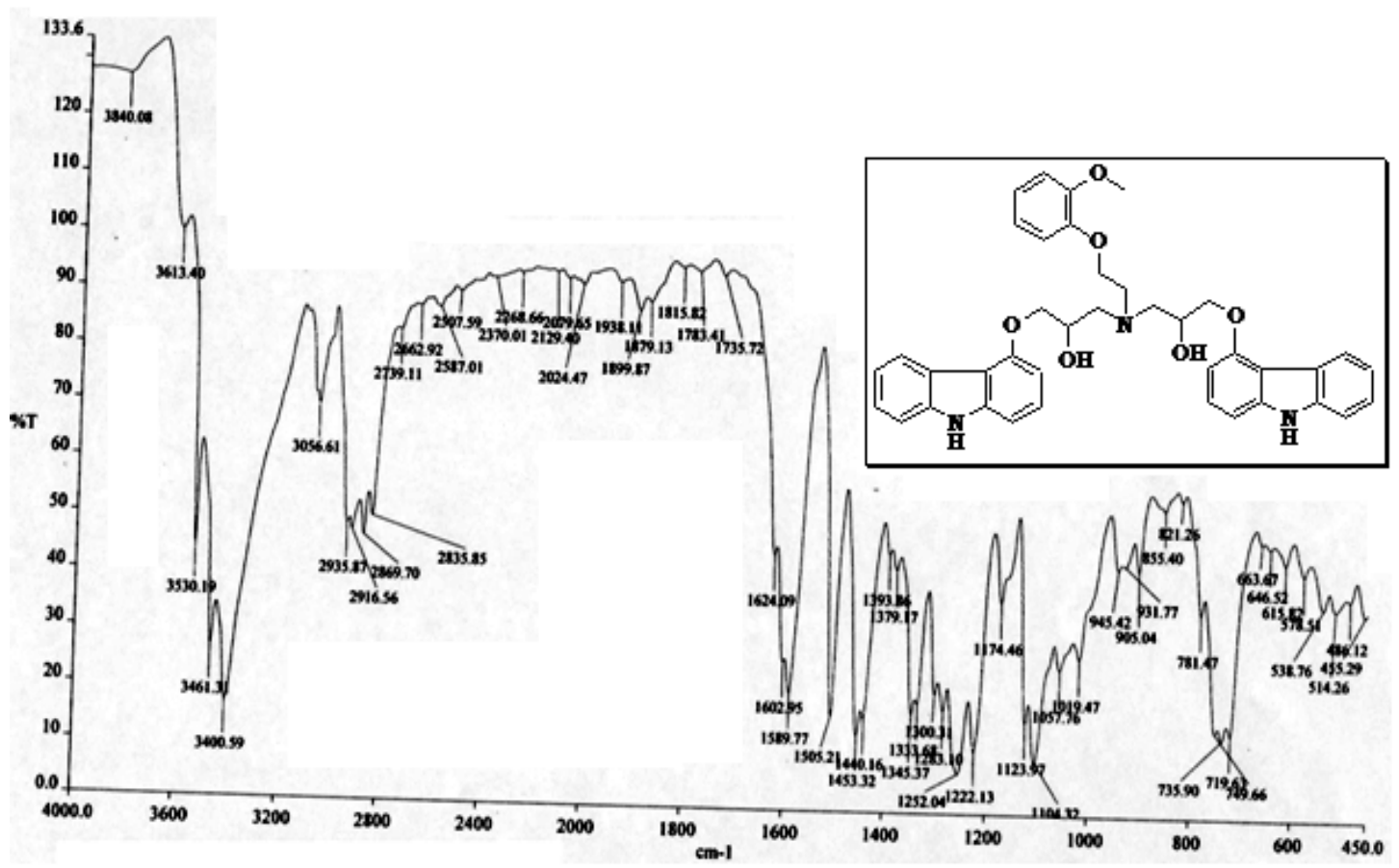

Figure 13. (3e) IR 

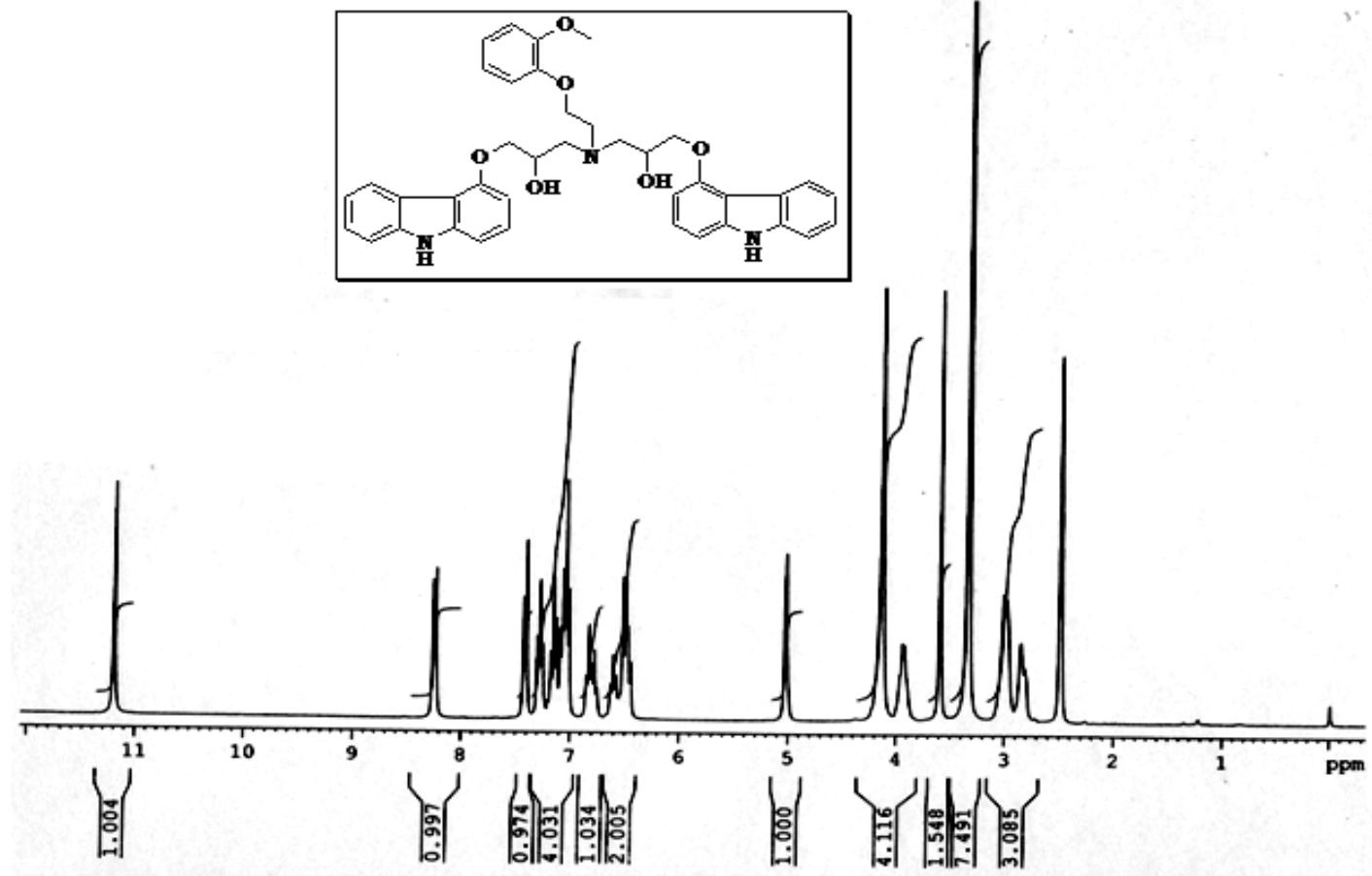

Figure 14. (3f) 1HNMR

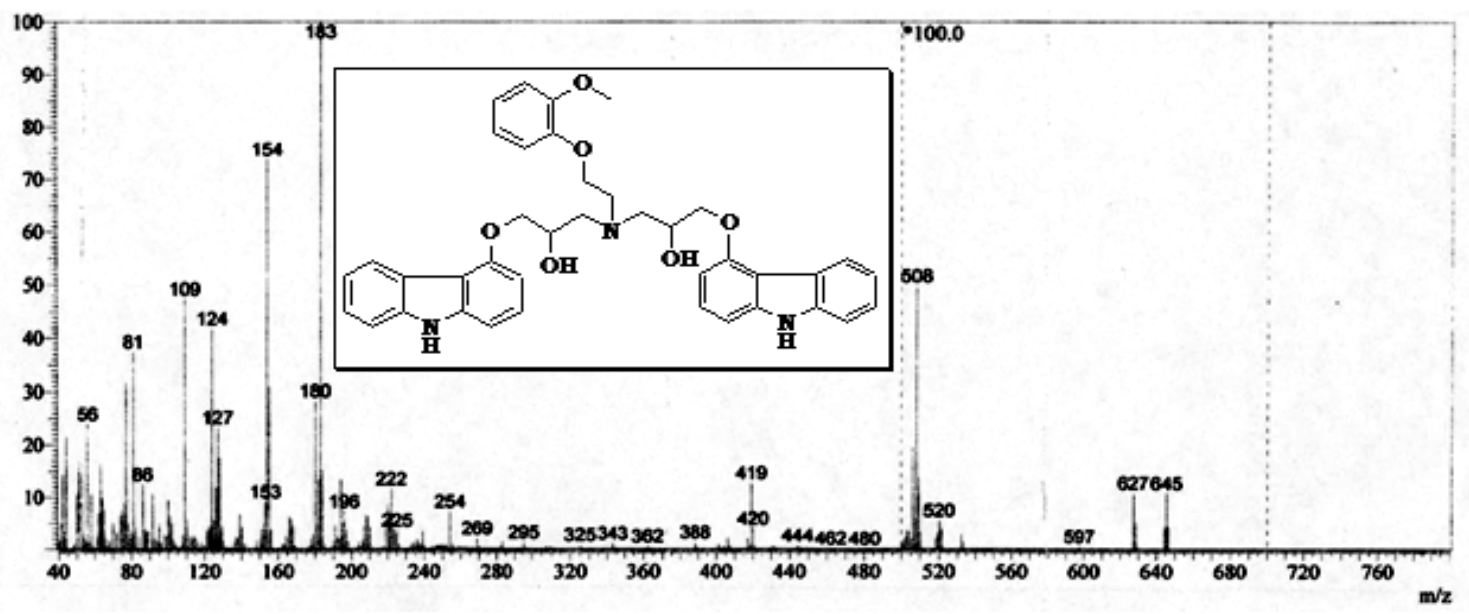

Figure 15. (3f) Mass

\section{REFERENCES}

[1] Main B G \& Tucker H, In Medicinal Chemistry: the role of Organic chemistry in Drug Research of $\beta$-blockers: Roberts $S$ M \& Price B J, Eds, Academic Press: London, 1985.

[2] Khupse N D \& Anil Kumar, Ind J of Chem., 49A, 2010, 635-48

[3] Howe R, Crowther A F, Stephenson J S, Rao B S \& Smith L H, J Med Chem, 11, 1968, 1000.

[4] Crowther A F \& Smith L H, J Med Chem, 11, 1968, 1009.

[5] Howe R \& Rao B S, J Med Chem, 11, 1968, 1118 and references cited therein.

[6] (a) Powell J R, Wainer I W \& Drayer D E, Drug Stereochemistry Analytical Methods and Pharmocology, Dekker M, USA, 1988; (b) Connolly M E, Kersting F \& Bollery C T, Prog Cardiovas Dis, 19, 1976, 203.

[7] (a) Rabkin R, Stables D P, Levin N W \&Suzman M M, Am J Cardiol, 18, 1966, 370; (b) Bestermann E M M \& Friedlander D H, Postgrad Med J, 41, 1965, 526; (c) Ross E J, Prichard B N C, Kaufmann L, Robertson A I G \& Harries B J, Br Med J, 1967, 191; (d) Prichard B N C \&Gillam P M S, Br Med J, 1964, 725; (e) Geroge C F, Prescriber's Journal 14, 1974, 93; (f) Sandler G \& Pistevos A C, Br Med J, b, 254.

[8] (a) Gas D \& Kregar M, Ann Inter Med, 70, 1970, 985; (b) Granville-Grossmann P \& Turner P, Lancet, 1966, 788; (c) Grosz H J, Lancet, 1972, 564; (d) Hadden D R, Montogomery 
D A, Shanks R G \& Weaver J A, Lancet, 1968, 852; (e) Morelli H F, Ann Inter Med, 78, 1973, 913; (f) Owen D A L \& Marsden C D, Lancet, 1965, 1259; (g) Weber R B \& Reinmuth O M, Neurology, 22, 1972, 366; (h) Young R R, Gowen J H \& Shahani B T, N Engl J Med, 293, 1975, 950.

[9] Fritz W, Wolfgang K, Max T, Gisbert S, Egon R \& Karl D, DE 2,815,926 A1, Oct 18, 1979, Chem Abstr, 92, 1979, P128716e.
[10] Zoltan R, Jozsef B, Gyula S, Tamas G, Donáth V G, Norbert N, Kalman N, Judit C, Tibor S, Laszlo B, Imre D, Zoltan G, Kotay N P \& Peter S, EP 0,918,055 A1, May 26, 1999, ChemAbstr, 130, 1999, P352184r.

[11] Jean H, Sergey F, Judith A, Dolitzky B-Z, Shoshana B-V \&Ilan K, WO 02/00, 216 A1, Jan 3, 2002, ChemAbstr, 136, 2002, P90914e. 